\title{
THE DISTORTION OF A WATER MOLECULE IN ICE*
}

\author{
By E. Whalley \\ (Division of Chemistry, National Research Council, Ottawa, Ontario KIA oR9, Canada)
}

\begin{abstract}
The experimental evidence for the distortion of a water molecule when it is condensed to form ice is reviewed. The specific distortions considered are the changes in inter-nuclear distances, energy and its derivatives with respect to nuclear motion, and electrical moments and polarizabilities and their response to nuclear motion. Some of the properties of ice can be expanded as Fourier or Taylor series in the ratio $r / R$ of the $\mathrm{O}-\mathrm{H}$ to the $\mathrm{O}-\mathrm{O}$ distances, and these expansions are used to relate various properties of the intermolecular potential energy, of the electrical dipole moments, and of the polarizability. For example, the amplitude of the orientation polarization can be related to the infrared intensity of the fundamental and first overtone infrared bands.

RÉsumé. Distorsion des molecules d'eau dans la glace. Nous présentons les diverses données expérimentales mettant en évidence la distorsion d'une molécule d'eau quand elle est condensée sous forme de glace. Nous avons considéré les distorsions spécifiques correspondant aux variations des distances entre les noyaux, l'énergie et ses dérivées par rapport à tout déplacement des noyaux, et les moments électriques et la polarisation ainsi que leur variation lors du mouvement des noyaux. Certaines propriétés de la glace peuvent être développées en série de Fourier et de Taylor en fonction du rapport $r / R(r:$ distance $\mathrm{O}-\mathrm{H} ; R:$ distance $\mathrm{O}-\mathrm{O})$ et ses développements sont utilisés pour relier diverses propriétés à l'énergie potentielle intermoléculaire, au moment dipolaire et à la polarisation. Par exemple, l'intensité et l'orientation de la polarisation peuvent être reliées à l'intensité des deux premières bandes du spectre infra-rouge.

Zusammenfassung. Die Verzerrung eines Wassermoleküls in Eis. Es wird ein Überblick über die experimentellen Beweise für die Verzerrung eines Wassermoleküls bei der Kondensation zu Eis gegeben. Folgende besonderen Verzerrungen werden betrachtet: die Änderung der zwischennuklearen Abstände, die Energie und deren Ableitungen in bezug auf die Kernbewegung, sowie die elektrischen Momente und Polarisierbarkeiten und ihre Antwort auf die Kernbewegung. Einige der Eiseigenschaften können als Fourier- oder Taylorreihen nach dem Verhältnis $r / R(\mathrm{O}-\mathrm{H}-\mathrm{zu} \mathrm{O}-\mathrm{O}-\mathrm{Abstand})$ entwickelt werden. Diese Entwicklungen werden benützt, um verschiedene Eigenschaften der intermolekularen potentiellen Energie, der elektrischen Dipolmomente und der Polarisierbarkeit miteinander zu verbinden. So kann zum Beispiel der Betrag der Orientierungspolarisation mit der Intensität der Infrarotbande der Grundschwingung und ersten Ober-
schwingung verknüpft werden.
\end{abstract}

\section{Introduction}

The central problem in attempting to understand the properties of ice is to understand the interaction of water molecules. This interaction can be measured in many different ways, and in the gas, liquid, and many solid phases, particularly if the clathrate hydrates are included. All of these ways amount to measurements of the distortion of the molecules caused by their interaction, as made evident in many different properties. Much information has been obtained during the past several decades on the distortions caused by the interaction of molecules, but no systematic study appears to have been made of any molecule. Water is undoubtedly the molecule that has been most investigated, and the distortion has some very spectacular effects. Among the more prominent of these are the following: the decrease of the $\mathrm{O}-\mathrm{H}$ stretching frequency of dilute $\mathrm{HDO}$ in $\mathrm{D}_{2} \mathrm{O}$ from $3890 \mathrm{~cm}^{-1}$ in the vapor (Benedict and others, 1956) to $3270 \mathrm{~cm}^{-1}$ at $100 \mathrm{~K}$ (Haas and Hornig, i 960 ; Bertie and Whalley, 1964 ); an increase of the absorption intensity due to the $\mathrm{O}-\mathrm{H}$ stretching oscillations by a factor of about $3^{\circ}$ (Ikawa and Maeda, 1968; Bertie and others, r969; Schaaf and Williams, 1973); and an increase of the dipole moment by a factor of between 1.33 and r.63 (see Section 2.3.2. I). These spectacular changes occur when water condenses but not when methane, for example, condenses, largely because the water-water interaction differs radically from the methanemethane interaction. It has the characteristics of a weak chemical bond, whereas the methane-methane interaction is typical of the interaction between saturated molecules. While weak chemical bonding occurs also in other molecules, such as the halogens (for example, Wong and Whalley, 1972, and references quoted there), it has not been as well studied. A critical review of what is known about the distortion in ice is therefore timely.

* N.R.C. No. 16703 . 
The changes of properties caused by the distortion are, of course, related to one another in that they are all caused by the changes of the wave function. Some of the changes are quite directly related to one another. For example, the properties of ice can be considered as a function of the $\mathrm{O}-\mathrm{H}$ distances, all $\mathrm{O}-\mathrm{H}$ distances being the same. If the $\mathrm{O}-\mathrm{H}$ distance were zero, the crystal would be composed of neon atoms, when it is the equilibrium distance $r_{0}$ it is ice, and when it is a half of the $\mathrm{O}-\mathrm{O}$ distance $R$, the hydrogen bonds are centro-symmetric and the local point symmetry of an oxygen atom is $T_{\mathrm{d}}$. When the $\mathrm{O}-\mathrm{H}$ distance is expanded to equal $R-r_{0}$ it is again ice, and when it equals the $\mathrm{O}-\mathrm{O}$ distance the crystal is again composed of neon atoms. These considerations suggest that the properties of ice can be expanded as a Fourier or Taylor series in the ratio of the $\mathrm{O}-\mathrm{H}$ distance to the $\mathrm{O}-\mathrm{O}$ distance. Then, properties that otherwise may seem unconnected can be related to one another. For example, if the dipole moment of a molecule can be expanded with only one term, the dipole moment and its derivatives with respect to the $\mathrm{O}-\mathrm{H}$ distance can be related by a single parameter. Thus the orientation polarization can be related to the intensity of the $\mathrm{O}-\mathrm{H}$ stretching vibrations, both fundamental and combination. In Section 3 , these principles will be explored and applied to ice.

\section{EXPERIMENTAL EVIDENCE FOR THE Distortion}

\section{I. Nuclear geometry}

Properties of the nuclear geometry of the isolated molecule have been determined by Benedict and others (1956) from an analysis of the infrared absorption spectrum. The "equilibrium" geometry for both $\mathrm{H}_{2} \mathrm{O}$ and $\mathrm{D}_{2} \mathrm{O}$ is

$$
\begin{aligned}
& r_{\mathrm{e}}=0.95^{8} 4 \AA, \\
& \theta_{\mathrm{e}}=104.45^{\circ},
\end{aligned}
$$

where $r$ is the $\mathrm{O}-\mathrm{H}$ distance, $\theta$ the $\mathrm{H}-\mathrm{O}-\mathrm{H}$ angle, and subscript e indicates the "equilibrium" values. The mean and root-mean-square values in the ground vibrational state are

$$
\begin{aligned}
& \langle r\rangle_{0}=0.9724 \AA \text { for } \mathrm{H}_{2} \mathrm{O} \text {, } \\
& =0.9686 \AA \text { for } \mathrm{D}_{2} \mathrm{O} \text {, } \\
& \langle\theta\rangle_{0}=104.63^{\circ} \text { for } \mathrm{H}_{2} \mathrm{O} \text {, } \\
& =104.57^{\circ} \text { for } \mathrm{D}_{2} \mathrm{O} \text {, } \\
& \left\langle r^{2}\right\rangle_{0}{ }^{\frac{1}{2}}={ }_{1} .026 \text { I for } \mathrm{H}_{2} \mathrm{O} \text {, } \\
& =1.0162 \text { for } \mathrm{D}_{2} \mathrm{O} \text {, } \\
& \left\langle\theta^{2}\right\rangle_{0^{3}}=\mathrm{I} 12.72^{\circ} \text { for } \mathrm{H}_{2} \mathrm{O} \text {, } \\
& =\mathrm{III} .94^{\circ} \text { for } \mathrm{D}_{2} \mathrm{O} \text {, }
\end{aligned}
$$

according to Kuchitsu and Bartell's (I962) analysis.

Neither the O-H nor the O-D distance in ice Ih appears to have been measured accurately, and there is no direct measurement of the $\mathrm{H}-\mathrm{O}-\mathrm{H}$ angle. The O-D distance of I.o $\AA$ as measured by neutron diffraction (Peterson and Levy, 1957) appears to be about $0.03 \AA$ too big (Whalley, r 1974) (see below) for reasons that are not well understood. The reason that the angle is not known is that the orientational disorder ensures that there are three possible hydrogen positions at each end of the $\mathrm{O}-\mathrm{O}$ bonds, each slightly off the $\mathrm{O}-\mathrm{O}$ line, and the deviation of the hydrogen nucleus from the $\mathrm{O}-\mathrm{O}$ line is determined by the difference between the $\mathrm{O}-\mathrm{O}-\mathrm{O}$ and $\mathrm{H}-\mathrm{O}-\mathrm{H}$ angles. The mean deviation of the hydrogen atoms from the $\mathrm{O}-\mathrm{O}$ line is of the magnitude of $0.04 \AA$, which is only a small fraction of the root-meansquare amplitude in the same direction due to the bending and rotational oscillations. Chidambaram ( $196 \mathrm{I}$ ) has shown quantitatively that this small amplitude of disorder is not detectable by current neutron diffraction experiments. Accurate measurements of the angle can therefore be made only on an ordered phase of ice. 
Neutron diffraction measurements at $c$. I oo $\mathrm{K}$ have been done on single crystals of $\mathrm{D}_{2} \mathrm{O}$ ice II and IX by Kamb and others (I97 I) and LaPlaca and others (I973) and the results are summarized in Table I. In ice II, the four non-equivalent $\mathrm{O}-\mathrm{D}$ distances are not significantly different, and in particular the great increase over the value in the vapor implied by the distance I.o $44 \AA$ and great decrease implied by the distance $0.937 \AA$ are almost certainly not real. The crystals of ice II that were examined were twinned (Kamb and others, I97I), which is not surprising as they can be grown only from another solid and not from the liquid, and the twinning reduced the accuracy of the atomic positions. The ice IX crystals (LaPlaca and others, 1973) were of much higher quality, and the results are thought to be highly reliable. The mean O-D distance is therefore about o.o $44 \AA$ bigger than in the vapor and the D-O-D angle about $\mathrm{I}^{\circ}$ bigger. A comparison of many properties of ice I, II, and IX (Whalley, ${ }_{1976)}$ strongly suggests that the mean O-D distance in ice I is greater than in ice II and IX by about $0.00 \mathrm{I}-0.002 \AA$. It follows from this that the $\mathrm{O}-\mathrm{D}$ bond in $\mathrm{D}_{2} \mathrm{O}$ ice $\mathrm{I}$ is elongated from the vapor value by about $0.016 \AA$.

Table I. Distances and angles calculated from mean nuclear positions in $\mathrm{D}_{2} \mathrm{O}$ Ice II AND IX AS DETERMINED BY SINGLE-CRYSTAL NEUTRON DIFFRACTION

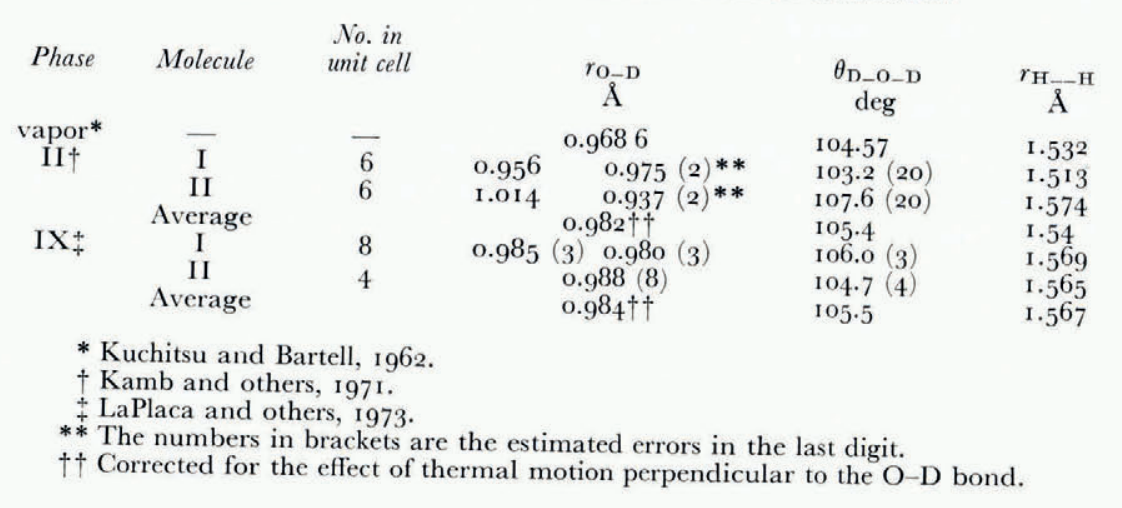

\subsection{Potential and kinetic energy}

\subsection{Total energy}

The energy per molecule decreases, when ice is formed, by the heat of vaporization, which in $47.34 \mathrm{I} \pm 0.015 \mathrm{~kJ} \mathrm{~mol}^{-1}$ at o $\mathrm{K}$ (Whalley, 1957). The changes in the kinetic energy of the nuclei due to the change of vibrational frequencies contribute significantly to this quantity (Whalley, I958, 1973). The translational kinetic energy is zero in the gas at o $\mathrm{K}$, but is $3.05 \mathrm{~kJ} \mathrm{~mol}^{-1}$ in the crystal. The rotational kinetic energy of para-water, whose nuclear spinwave function is antisymmetric, is zero in the gas, but $13.5 \mathrm{~kJ} \mathrm{~mol}^{-1}$ in the crystal. The kinetic energy of the $\mathrm{O}-\mathrm{H}$ stretching motions decreases by $5.27 \mathrm{~kJ} \mathrm{~mol}^{-1}$, and that of the bending vibrations increases by about $0.3 \mathrm{~kJ} \mathrm{~mol}^{-1}$. The total kinetic energy increases by I I. $6 \mathrm{~kJ} \mathrm{~mol}{ }^{-1}$. The sum of the potential energy of the nuclei and the kinetic and potential energies of the electrons decreases therefore by $58.9 \mathrm{~kJ} \mathrm{~mol}^{-1}$ when ice is formed at $\mathrm{o} \mathrm{K}$.

By the virial theorem for particles interacting by Coulomb forces the kinetic energy of the electrons and nuclei increases by $47.34 \mathrm{~kJ} \mathrm{~mol}^{-1}$, and the potential energy of the electrons and nuclei decreases by twice this value, or $94.68 \mathrm{~kJ} \mathrm{~mol}^{-1}$. As the kinetic energy of the nuclei increases by I $1.6 \mathrm{~kJ} \mathrm{~mol}^{-1}$, the kinetic energy of the electrons increases by $35.7 \mathrm{~kJ} \mathrm{~mol}^{-1}$. 


\subsubsection{Effect of stretching the $\mathrm{O}-\mathrm{H}$ bonds on the energy}

When water condenses, the frequency of the $\nu_{\mathrm{I}}$ (symmetric) stretching vibration decreases from $38_{32}(2764) \mathrm{cm}^{-1}$ (Benedict and others, 1956), where the bracketed frequency is for $\mathrm{D}_{2} \mathrm{O}$, to $3083(2295) \mathrm{cm}^{-1}$ at $100 \mathrm{~K}$ (Wong and Whalley, 1975) when the $\nu_{\mathrm{x}}$ vibrations are in phase in all molecules (Wong and Whalley, 1975; McGraw and others, 1977; paper in preparation*) and to $c .3420(c .2547) \mathrm{cm}^{-1}$ when neighboring molecules vibrate out of phase (Whalley, 1977). The mean should be approximately the frequency of the $\nu_{\mathrm{I}}$ vibration of a molecule that is vibrationally uncoupled from its neighbours. It is $325^{2}\left(24^{2 \mathrm{I}}\right) \mathrm{cm}^{-1}$. Recently, Ritzhaupt and Devlin (1977) have reported the infrared spectrum of the $\nu_{1}$ and $\nu_{3}$ vibrations of a $\mathrm{D}_{2} \mathrm{O}$ molecule in dilute solution in amorphous ice as 2378 and $2473 \mathrm{~cm}^{-1}$ and have obtained tentative frequencies for ice Ic (private communication from J. P. Devlin $\dagger$ ) of $236 \mathrm{o}_{-5}^{+2}$ and $2445 \mathrm{~cm}^{-1}$. There is as yet little direct information about the anharmonicities. Haas and Hornig (1960) have reported the harmonic constant $\nu_{\mathrm{e}}$ as $3525 \mathrm{~cm}^{-1}$ and the anharmonic constant $\nu_{\mathrm{e}} x_{\mathrm{e}}$ as $c$. $-\mathrm{I} 25 \mathrm{~cm}^{-1}$. The experimental basis for this interpretation has, however, been challenged (Kroh and Ron, 1975). Based on much better spectra, which do not confirm Haas and Hornig's, they propose $\nu_{\mathrm{e}}=3630 \mathrm{~cm}^{-1}, \nu_{\mathrm{e}} x_{\mathrm{e}}=-300 \mathrm{~cm}^{-1}$. The corresponding values for the isolated molecule are 3889 and $-83 \mathrm{~cm}^{-1}$ (Benedict and others, 1956). However, the interpretation of the overtone spectrum of ice and hence the vibrational constants, is not fully established.

\subsection{Electrostatic moments}

The electric potential outside itself caused by a molecule can be written in terms of the electrostatic moments, namely the charge $e$, components $\mu_{x}$, etc., of the dipole moment and the principal values $\theta_{x x}, \Omega_{x x x}$, etc., of the quadrupole, octopole, etc., moments which are defined as

$$
\begin{aligned}
e & =\sum_{i} e_{i}, \\
\mu_{x} & =\sum_{i} e_{i} x_{i}, \\
\theta_{x x} & =\sum_{i} e_{i} r_{i}{ }^{2} P_{2}\left(x_{i} / r_{i}\right), \text { etc., } \\
\Omega_{x x x} & =\sum_{i} e_{i} r_{i}{ }^{3} P_{3}\left(x_{i} / r_{i}\right), \text { etc. },
\end{aligned}
$$

where $e_{i}$ are the charges at positions $\mathbf{r}_{i}=\left(x_{i}, y_{i}, z_{i}\right)$ and $P_{n}$ is the $n$th Legendre polynomial. The moments can be determined unambiguously in the gas phase, but not in condensed phases because the molecules are too close together. Different properties may measure different moments, and a careful analysis is necessary.

\subsection{Charge}

Strictly speaking ice I has no symmetry. Consequently, the molecules could be charged, some positively and some negatively. No measurements exist which indicate the magnitude of the charge, but it is likely to be small for the following reason. The hypothetical ordered cubic ice that has all its molecular axes parallel to one another belongs to space group $I_{41} m d$, $C_{4 \mathrm{v}^{\mathrm{V}}}^{\mathrm{II}}$. The molecules are transformed into one another by a $4_{\mathrm{I}}$ rotation and so cannot be charged. When the molecules are vibrating in the $\nu_{\mathrm{I}}$ mode with all molecules in phase they are also transformed into one another by a $4_{1}$ rotation, and so both must still be uncharged. The in-phase $v_{3}$ vibrations are degenerate because the potential energy is invariant on changing

* Paper entitled "Extent of coupling of the $\nu_{1}$ vibrations in ice", by E. Whalley.

$\uparrow$ I am grateful to Dr Devlin for permission to quote this information. 
the phase of alternate molecules. The character for the $4_{\mathrm{I}}$ rotation is $\mathrm{o}$, and consequently, charge cannot be transferred between molecules during this vibration. By analogy, it seems likely that the molecular charges are small in the disordered phases, but there is no direct experimental evidence.

\subsubsection{Dipole moment}

The dipole moment $\mathbf{M}$ of a crystal is the sum of the moments $\mu_{i}$ of the molecules

$$
\mathbf{M}=\sum_{i} \mu_{i}
$$

and if the molecular orientations are known and the dipole moment of a crystal can be measured, the dipole moment as defined by this equation can be determined. The dipole moment of the crystal cannot be measured in practice, but the mean-square dipole moment can be calculated from the static dielectric permittivity. The mean-square dipole moment can in principle be related to the geometry, and so the dipole moment of a molecule can be obtained. This moment is measured by the change of dipole moment when the molecular orientations change in such a way as to preserve the ice rules, and so it measures the dipole moment that reorients with a molecule when the ice rules are preserved.

A second dipole moment can be measured by the change of dipole moment of the crystal when one molecule rotates through a small angle, and all the other molecules stay still. The mean-square value of this moment over all molecules can be measured by the infrared intensity of the rotational vibrations. It may not be closely related to the moment determined from dielectric properties.

The change of dipole moment with $\mathrm{O}-\mathrm{H}$ distance can be determined from the intensity of the fundamental, and the second-, third-, etc., order infrared spectra of the O-H stretching vibrations. Its change with $\mathrm{O}-\mathrm{O}$ distance can be obtained either from the effect of pressure on the permittivity or from the intensity of the translational vibrations of the water molecules. The measured effect of pressure on the permittivity (Chan and others, 1965; Taubenberger and others, 1973) is not accurate enough to use at present, but the infrared intensity is.

\subsubsection{Dipole moment that reorients with the molecule}

According to Kirkwood's (r 939) theory the amplitude of the dielectric permittivity due to the orientation polarization of an isotropic dielectric is related to the molecular dipole moment $\mu$ by the relation

$$
\epsilon_{0}-\epsilon_{\infty}=2 \pi \mathcal{N} g \mu^{2} / k T, \quad \epsilon_{0} \gg \epsilon_{\infty} .
$$

In this equation $\mu^{2}$ is the ensemble average of the square of the dipole moment of a molecule, which is defined in terms of the moment $\mathbf{M}$ of a macroscopic specimen by Equation ( $\mathrm{I})$. The correlation parameter $g$ is defined by considering molecule I (say) embedded in a sphere of the specimen of radius $r$ which is itself embedded in a sphere of the specimen of radius $R$. Then

$$
g \mu^{2}=\lim _{\substack{r \rightarrow \infty \\ R / r \rightarrow \infty}} \sum_{i} \mu_{\mathrm{I}} \cdot \mu_{i} .
$$

Nagle (1978) has reviewed the problem of calculating $g$ for a model of ice Ih that obeys the ice rules. There has been some controversy (Gobush and Hoeve, I972; Rahman and Stillinger, 1972; Stillinger and Cotter, 1973; Nagle, 1974), but it now appears that $g$ is well approximated by 3.0o. A problem less easily solved is the value of the internal field that acts on a water molecule. Equation (2) is based on the Lorentz field. Others (Onsager and Dupuis, I960, I962; Slater, I941) have used the form

$$
\epsilon_{0}-\epsilon_{\infty}=\frac{4 \pi \mathcal{N} G \mu^{2}}{3 k T},
$$


where

$$
G \mu^{2}=\sum_{i} \mu_{1} \cdot \mu_{i}
$$

for a spherical specimen and for ice (Nagle, 1978),

$$
g=G \text {. }
$$

This equation assumes that the molecules experience the applied field without modification. Hollins (1964) has given a reason for supposing that the effective field might be less than the Lorentz field. Equation (4) predicts a value of $\mu^{2}$ that is 1.22 times greater than that of Equation (2). The actual internal field is not known, and Equation (2) will arbitrarily be used.

According to Johari and Whalley (1973)

$$
\epsilon_{0}-\epsilon_{\infty}=25400 \mathrm{~K} / T \text {, }
$$

so that

$$
g \mu^{2}=18.1 \mathrm{D}^{2} \text {. }
$$

As $g=3$,

$$
\mu=2.45 \mathrm{D} \text {. }
$$

( $\mathrm{I}$ Debye $(\mathrm{D})=1 \mathrm{I}^{-18}$ e.s.u. $\mathrm{cm} \approx 3 \times \mathrm{IO}^{-29} \mathrm{C} \mathrm{m}$.) The alternative equation, Equation (4), predicts that $\mu=3.00 \mathrm{D}$.

Accurate theoretical values of $g$ are not known for other phases of ice, at least partly because all of them appear to be orientationally more ordered than is described by the ice rules. The permittivity of ice VI (Johari and Whalley, I976) obeys the Curie-Weiss Law

$$
\epsilon_{0}-\epsilon_{\infty}=A /\left(T-T_{0}\right),
$$

with $A=29400 \mathrm{~K}$ (the value $3^{2} 300 \mathrm{~K}$ quoted in the paper is a transcription error) and $T_{0}=47 \mathrm{~K}$. This corresponds to a variation of $g \mu^{2}$ with temperature given by

$$
g \mu^{2}=\left(g \mu^{2}\right)_{\infty} T /\left(T-T_{0}\right),
$$

where $\left(g \mu^{2}\right)_{\infty}$ is the value of $g \mu^{2}$ extrapolated to infinite temperature. There is little doubt that ice VI is partly orientationally ordered at all finite temperatures and that $\left(g \mu^{2}\right)_{\infty}$ is the best estimate of the value of $g \mu^{2}$ for full orientational disorder. Its value is $16.7 \mathrm{D}^{2}$. An approximate value of $g$ for full disorder, which takes account of the effects of the fourmembered rings, is 2.34 (Johari and Whalley, r978). The corresponding value of $\mu$ is $2.67 \mathrm{D}$ if Equation (2) is correct and $3.27 \mathrm{D}$ if Equation (4) is correct.

The dipole moment of an isolated water molecule is I.85 $_{5} \mathrm{D}$ (Clough and others, I973) so that intermolecular interaction in both ice I and VI greatly changes the charge distribution.

\subsubsection{The dipole moment that follows the orientational oscillations of the molecule}

When the axis of a water molecule oscillates, the dipole moment of the crystal changes, and the rate of change with angle is the moment that oscillates with the molecule. The oscillations of water molecules in ice occur at a frequency of about $22 \times 10^{12} \mathrm{~Hz}$ or a rate of about one oscillation in about $45 \times 10^{-15} \mathrm{~s}$. They cause infrared absorption in the range $525^{-1} 0_{0} \mathrm{~cm}^{-1}$ (Bertie and others, I 969 ), and the integrated absorption intensity depends on the magnitude of the oscillating dipole moment. Each mole of ice has $3 \mathcal{N}$ normal rotational oscillations where $\mathcal{N}$ is Avogadro's number, each of which involves many molecules. The integrated intensity of absorption $A_{i}$ of a typical oscillation $i$ is defined as

$$
A_{i}=\frac{\mathrm{I}}{\rho} \int K(\nu) \mathrm{d} \nu,
$$


where $\rho$ is the density and $K(\nu)$ the absorptivity at frequency $\nu$ defined by the relation between the intensities of light $I_{0}$ and $I$ before and after travelling a distance $x$ in the sample,

$$
I=I_{0} \exp -K x \text {. }
$$

It is related to the change of dipole moment during the oscillation by the relation

$$
A_{i}=\left(\frac{n^{2}+2}{3}\right)^{2} \frac{\mathrm{I}}{n} \frac{\pi}{3^{2}}\left(\frac{\partial \mu}{\partial Q_{i}}\right)^{2},
$$

where the factor $\left[\left(n^{2}+2\right) / 3\right]^{2} / n$ allows for the effect of the material on the electric field of the light wave assuming the Lorentz field, $n$ is the refractive index at the frequency of measurement due to all polarizations except that due to the oscillation being considered, $c$ the speed of light, $\mu$ the dipole moment of the crystal, and $Q_{i}$ the normal coordinate of the $i$ th oscillation. It follows that

$$
\left(\frac{\partial \mu}{\partial Q_{i}}\right)^{2}=\frac{3 c^{2}}{\pi}\left(\frac{3}{n^{2}+3}\right)^{2} n A_{i} .
$$

If the individual absorption bands are narrow enough that the refractive index does not change appreciably over them, the sum of the right-hand side over all $i$ can be replaced by an integral over the whole absorption band. Then

$$
\sum_{i}\left(\frac{\partial \mu}{\partial Q_{i}}\right)^{2}=\frac{3 c^{2}}{\pi} \int_{\text {band }}\left(\frac{3}{n^{2}+2}\right)^{2} n \kappa \mathrm{d} \nu .
$$

This equation differs from the equation usually used in that the factor $\left[3 /\left(n^{2}+3\right)\right]^{2} n$ is within the integral sign because the band is a composite of many oscillators. It is readily shown (Klug and Whalley, 1973) that the sum on the left-hand side of Equation (9) is

$$
\sum_{i}\left(\frac{\partial \mu}{\partial Q_{i}}\right)^{2}=\mathcal{N} \sum_{\alpha} \frac{\mu_{\alpha}^{2}}{I_{\alpha}},
$$

where $\mu_{\alpha}$ is the dipole moment of the molecule perpendicular to the $\alpha$ principal axis and $I_{\alpha}$ the moment of inertia about that axis. The intensity of absorption is therefore independent of the coupling of the motions about the principal axes.

The integrated intensity of the rotational vibrations has been measured by Ikawa and Maeda (I968) at $c$. I I $\mathrm{K}$ and by Bertie and others (I969) at $c$. roo K by measuring the transmission by thin films prepared by evaporation onto a cold plate. Ikawa and Maeda measured the thickness by recording the interference fringes at $9000 \mathrm{~cm}^{-1}$ during deposition and measured several thicknesses in the range $0.2-\mathrm{I} .7 \mu \mathrm{m}$ for $\mathrm{H}_{2} \mathrm{O}$. The Beer's law plots were linear and passed through the origin, which suggests that reflection effects were unimportant. Bertie and others ( 1969 ) measured many films of unknown thicknesses in overlapping frequency regions, scaled them all to obtain an optical density spectrum for a single unknown thickness, and determined that thickness $l$ by applying the Kramers-Kronig relation

$$
\Delta n=\frac{2.303}{2 \pi^{2} l} \int_{\text {band }} \frac{\chi}{\nu^{2}} \mathrm{~d} \nu,
$$

where $\Delta n$ is the (known) change of refractive index across all the infrared bands and $\chi$ the optical density. The film was $0.86 \mu \mathrm{m}$ thick, and the integrated intensity of the rotational vibrations agreed with Ikawa and Maeda's, which was $16.5 \times \mathrm{IO}^{3} \mathrm{~cm} \mathrm{mmol}^{-1}$, within $3 \%$. The optical constants have also been measured by Schaaf and Williams ( 1973) at $266 \mathrm{~K}$ by measuring the reflectance at nearly normal incidence, and the real and imaginary parts of the complex refractive index were calculated by the Kramers-Kronig relation. The integrated intensity was calculated from the tabulated imaginary part of the refractive index. The three values are summarized in Table II. The agreement is within the experimental uncertainty, and the value $(\mathrm{r} 8.5 \pm 2) \times \mathrm{IO}^{3} \mathrm{~cm} \mathrm{mmol}^{-1}$ encompasses them all. 
TABle II. Integrated absorptivities $\rho^{-1} \int K \mathrm{~d} v$ OF the $\mathrm{O}-\mathrm{H}$ stretching $v O H$ AND ROTATIONAL $\nu_{\mathrm{R}}$ VIBRATIONS OF ICE

Author
Ikawa and Maeda (1968)
Bertie and others (1969)
Schaaf and Williams (1973)

$\begin{aligned} & T \\ & \mathrm{~K} \\ & \approx \\ & \approx 110 \\ & \approx \\ & 266\end{aligned}$

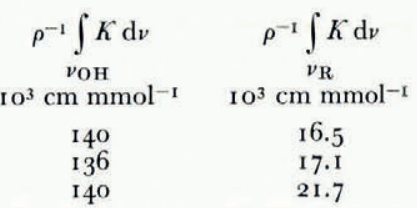

Because about $\mathrm{IO}^{24}$ vibrations per mole are being observed, account ought to be taken of the effect of the internal field as outlined above. In fact, using a constant value of the refractive index equal to the mean over the band makes a difference only $\mathrm{I}-2 \%$. Hence

$$
\sum_{k}\left(\frac{\partial \mu}{\partial Q_{k}}\right)^{2}=\mathrm{I} 5 \pm 2 \times \mathrm{IO}^{3} \mathrm{~cm} \mathrm{mmol}^{-1} .
$$

The band no doubt contains motions about all axes, but only motions about the two axes perpendicular to the molecular axis contribute to the intensity. The moments of inertia about these axes in the ground vibrational state in the gas are $(1.929$ and 3.013$) \times 10^{-40} \mathrm{~g} \mathrm{~cm}^{2}$ (Benedict and others, 1956) and these are an adequate approximation for the moments of inertia in the crystal. It follows that

$$
\mu_{\theta}^{2} \equiv\left(\frac{\partial \mu}{\partial \theta}\right)^{2}=\mathrm{I} .62 \pm 0.2 \mathrm{D}^{2},
$$

or

$$
\mu_{\theta}=1.27 \pm 0.08 \mathrm{D} \text {. }
$$

Ikawa and Maeda calculated I.35 D by ignoring the effect of the refractive index.

This value is about 0.69 of the vapor value and $0.5^{2}$ or 0.42 of the moment that reorients with the molecule (see Section 2.3.2.I). There is little doubt that the dipole that oscillates with the molecule is much smaller than the dipole that rotates with the molecule and is even much smaller than the dipole of the isolated molecule.

\subsubsection{Change of the dipole moment with the $\mathrm{O}-\mathrm{H}$ stretching motion}

The integrated intensity of the $\mathrm{O}-\mathrm{H}$ stretching bands in ice has been measured by Ikawa and Maeda (I 968 ) at $c$. Ioo K, Bertie and others (1969) at $c$. Ioo K, and Schaaf and Williams (1973) at $266 \mathrm{~K}$ all as described in Section 2.3.2.2, and the values are compared in Table II. The agreement is well within experimental uncertainty. By allowing for the internal field using the mean refractive index over the band, the $\operatorname{sum}\left(\partial \mu / \partial Q_{i}\right)^{2}$ over all vibrations is $116 \times 10^{3}$ $\mathrm{cm} \mathrm{mmol}{ }^{-1}$. Hence, following Ikawa and Maeda's calculation, the change of dipole moment when an $\mathrm{O}-\mathrm{H}$ bond stretches is $\pm 3.6 \mathrm{D} \AA^{-1}$ in an unknown direction. If the directions of the changes of the dipole-moment vectors when the two bonds in a water molecule lengthen are at the angle $\beta$ to one another, the change of dipole moment of a water molecule in ice during a $\nu_{\mathrm{I}}$ vibration is $7.2 \cos \frac{1}{2} \beta \mathrm{D} \AA^{-1}$. If the moment is along the $\mathrm{O}-\mathrm{H}$ bond, the value is $\pm 4 \cdot 4$ $\mathrm{D} \AA^{-1}$. The change of dipole moment when the $\mathrm{O}-\mathrm{H}$ bond of an isolated water molecule stretches is $0.67 \mathrm{D} \AA^{-1}$, so its value is greatly enhanced when ice is formed.

Only limited information is available about the second derivative of the dipole moment with respect to the in-phase stretching motion. It is related to the properties of the isolated bonds by the relation 


$$
\frac{\partial^{2} \mu}{\partial r^{2}}=\sum_{i} \frac{\partial^{2} \mu}{\partial r_{i}{ }^{2}}+\sum_{\substack{i, j \\ \text { in } \\ \text { same } \\ \text { molecule }}} \frac{\partial^{2} \mu}{\partial r_{i} \partial r_{j}}+\sum_{\substack{i, j \\ \text { in } \\ \text { adjacent } \\ \text { molecules }}} \frac{\partial^{2} \mu}{\partial r_{i} \partial r_{j}},
$$

where $r_{i}$ is the length of the $i$ th $\mathrm{O}-\mathrm{H}$ bond, and all $r_{i}$ change in phase. Nothing is known about the second and third terms on the right side of Equation (I I). An approximate value of $\partial^{2} \mu / \partial r_{\mathrm{OH}^{2}}$ for the stretching of a single $\mathrm{O}-\mathrm{H}$ bond has been obtained (Whalley, r 973 ) from the binary overtone intensity measured by Ockman (1958) and the third-order potential constant determined by Haas and Hornig (I96o). It is \pm Io $\mathrm{D} \AA^{-2}$, the sign being the same as that of the first derivative. It corresponds to $\pm \mathrm{I}_{2} \mathrm{D}^{-2}$ for the change of dipole moment during the $\nu_{I}$ stretching motion. However, the third-order potential constant has been disputed recently (Kroh and Ron, 1975).

\subsubsection{Change of the dipole moment with $\mathrm{O}-\mathrm{O}$ stretching motion}

The change of dipole moment of an $\mathrm{O}-\mathrm{H}$ bond when it stretches is, from the absorption intensity of the translational vibrations $\pm 2 \mathrm{D}^{-1}$ (Klug and Whalley, 1973). From the definition of the dipole moment in Equation ( $\mathrm{I}$ ) and assuming that the dipole moment change is directed along the $\mathrm{O}-\mathrm{O}$ bond, the change of dipole moment of a molecule when all the $\mathrm{O}-\mathrm{O}$ bonds are compressed uniformly is

$$
\partial \mu / \partial R= \pm 2.3 \mathrm{D} \AA^{-1}
$$

where $R$ is the $\mathrm{O}-\mathrm{O}$ distance. The compressibility of ice is I I $\mathrm{Mbar}^{-1}$ (Leadbetter, I965), so that the rate of change of the dipole moment with pressure, which is $-\frac{1}{3}(\partial \mu / \partial R) R \kappa$ where $\kappa$ is the compressibility, is predicted to be

$$
\partial \mu / \partial p=\mp 23 \mathrm{D} \mathrm{Mbar}^{-1} \text {. }
$$

\subsubsection{Quadrupole moment}

There is at present no way of directly measuring the quadrupole or higher moments of a molecule in a condensed phase. A somewhat indirect method has however been used for the water molecules in clathrate hydrates. Clathrate hydrates are ice-like crystals that have large cages which enclose foreign molecules. These molecules can reorient in their cages against potential barriers that can be due either to repulsive (and perhaps attractive) forces between the molecules and the cage walls, or to electrostatic forces due to the interaction of the electric moments of the molecule with the electric field caused by the cage molecules. By measuring the rate of reorientation, an upper limit can be obtained for the hindering potential, and so an upper limit for the electrostatic field can be obtained. This in turn sets an upper limit to the electrostatic moments of the water molecules.

The experimental basis is that the activation energy for the reorientation of tetrahydrofuran in tetrahydrofuran clathrate hydrate, which has structure II, is $c .0 .3 \mathrm{kcal} \mathrm{mol}^{-1}$ or 0.02 I perg molecule ${ }^{-1}$ (Davidson and others, I964; Davies and Williams, I968), which corresponds to a field of $c$. O.or M e.s.u. $\mathrm{cm}^{-2}\left(c .3 \mathrm{MV} \mathrm{cm}^{-1}\right)$ if the electric field provided all the activation energy. The theoretical basis is Davidson's (I97I) calculation of the mean electric field at the centres of some of the cages due to the dipole and quadrupole moments of the water molecules. It turns out that the dipolar field averaged over a large number of orientational configurations is always small. Indeed, if all the molecules were uniformly distributed on the surface of a sphere, and if the angles between the radius vector of a molecule and its $\mathrm{O}-\mathrm{H}$ vectors were always tetrahedral, symmetry would require that the field at the centre of the cage be zero. In practice, this geometry cannot be exactly attained, and small resultant fields occur which are usually much less than the field of a water molecule acting 
alone. The fields of the molecular quadrupole moments do not cancel in the same way, and so the fields are sensitive to the quadrupole moments.

The more symmetrical cage of a structure-II hydrate is a hexakaidecahedron, and the mean dipolar field, assuming a molecular dipole moment of $1.84 \mathrm{D}$, was $0.0{ }_{5} \mathrm{M} \mathrm{e.s.u.} \mathrm{cm}^{-2}$ $\left(4.5 \mathrm{MV} \mathrm{cm}^{-1}\right)$. The actual moment of a water molecule is undoubtedly considerably greater than this (see Section 2.3.2.I), and so the actual field is considerably greater. The mean quadrupolar field, using the quadrupole moments calculated by Glaeser and Coulson ( 1965 ), the principle values of which, after subtracting the trace, are $(-0.8 \mathrm{I}, 0.57$, and 0.24$) \times \mathrm{IO}^{-26}$ e.s.u. $\mathrm{cm}^{2}$ relative to an origin on the oxygen atom, was $0.025 \mathrm{M}$ e.s.u. $\mathrm{cm}^{-2}\left(7.5 \mathrm{MV} \mathrm{cm}^{-1}\right)$. Because the actual field is at most about o.or $\mathrm{Me.s.u} . \mathrm{cm}^{-2}\left(3 \mathrm{MV} \mathrm{cm}{ }^{-1}\right)$, and the dipole moment of a molecule is certainly higher than was assumed, the quadrupole moment in structure-II hydrates must be a small fraction of that calculated for the vapor molecule. To present precision, it is indistinguishable from zero.

\subsection{Polarizability}

The polarizability $\alpha$ is a tensor quantity with principal components $\alpha_{x x}$, etc., and its rotational invariants, which are all that can be measured in ice because of the orientational disorder, are an isotropic $\alpha$ and an anisotropic $\gamma$, where

$$
\begin{aligned}
\alpha & =\frac{1}{3}\left(\alpha_{x x}+\alpha_{y y}+\alpha_{z z}\right), \\
\gamma^{2} & =\frac{1}{2}\left[\left(\alpha_{x x}-\alpha_{y y}\right)^{2}+\left(\alpha_{y y}-\alpha_{z z}\right)^{2}+\left(\alpha_{z z}-\alpha_{x x}\right)^{2}\right] .
\end{aligned}
$$

\subsection{Polarizability of the molecule}

The isotropic part of the polarizability of the isolated molecule can be determined from the refractive index of the vapor, and Zeiss and Meath (1975) have recently critically surveyed the measurements. The static polarizability is $\mathrm{I}_{2} 4^{27} \AA^{3}$, and the value at $5^{\mathrm{I}} 4.5 \mathrm{~nm}$ is $1.470 \AA^{3}$ (Murphy, 1977). Murphy (1977) has recently measured the depolarization ratio for the Rayleigh and the Raman rotational lines of water vapor and derived from them and the isotropic polarizability the principal polarizabilities. They are

$$
\begin{aligned}
& \alpha_{x x}=\mathrm{I} .5^{28}(\mathrm{I} 3) \AA^{3}, \\
& \alpha_{y y}=\mathrm{I} .4 \mathrm{I} 5(\mathrm{I} 3) \AA^{3}, \\
& \alpha_{z z}=\mathrm{I} .468(3) \AA^{3},
\end{aligned}
$$

where the numbers in brackets are the estimated uncertainties of the last figures, and the anisotropic invariant is

$$
\gamma=0.098 \AA^{3} \text {. }
$$

Ice is slightly birefringent, the refractive index for the ordinary wave for the sodium D line being o.oor 4 less than the refractive index for the extraordinary wave (Dorsey, 1940, p. 485). The mean of the principal dielectric constants at the sodium D line is 1.715 (Dorsey, I940, p. 485), which corresponds to a mean polarizability, or its isotropic invariant, of a water molecule of $1.50 \AA^{3}$, which is probably slightly higher than the value in the vapor.

The water molecules in ice Ih have 24 different orientations, all equally probable. These orientations form two sets of twelve, and the two sets are related by the symmetry operations of the space group $P 6_{3} / m m c$. If the coordination were perfectly tetrahedral, the anisotropic part of the polarizability would average out. Because the axial ratio $c / a$ of the unit cell is not exactly the value $(8 / 3)^{\frac{1}{2}}$ for perfect tetrahedral coordination, but is 1.6282 (LaPlaca and Post, I96o; Brill and Tippe, 1967) instead of I.633 o, and because second neighbors are not tetrahedrally arranged, the coordination is not perfect tetrahedral. The anisotropic part of the polarizability does not therefore average out exactly, and the internal field may be anisotropic. 
The effect of the internal field has been estimated by Minton (1972), and the difference between Minton's calculation and experiment has been used by Cummins and Dunmur (r973) to obtain \pm o.or $\AA^{3}$ as a very rough estimate the anisotropic invariant. Its reliability is quite uncertain. Orrtung and Meyers ( 1963 ) were unable to detect an anisotropy in the liquid from the Kerr constant.

Information about the anisotropic part of the polarizability tensor in the crystal can in principle be obtained from the intensity of the Raman scattering by the rotational oscillations. It can readily be shown that their integrated Raman intensity reduced by the Boltzmannand frequency factors, is proportional to $\gamma^{2}$. Their intensity has never been measured, but it is so weak that it was first detected only recently in ice Ih (Wong and Whalley, 1975; Scherer and Snyder, 1977), and in ice VIII (Wong and Whalley, 1976), although the corresponding band in the liquid has been known for forty years (Cross and others, 1937). This suggests that the anisotropy of the polarizability is smaller in the solid than in the liquid, and so is presumably smaller than in the vapor. This agrees with the relative values of very roughly $\pm 0.0 \mathrm{I}$ in the solid (Cummins and Dunmur, r973) and o.098 in the vapor (Murphy, 1977). However, the scattering intensity must be measured quantitatively to make this very tentative conclusion reliable.

\subsubsection{Oscillation of the polarizability with the $\mathrm{O}-\mathrm{H}$ stretching oscillations}

The magnitude of the oscillation of the polarizability of the water molecule during the $\mathrm{O}-\mathrm{H}$ stretching oscillations could be determined from the intensity of the Raman scattering by these oscillations relative to the intensity of the exciting light. This has not yet been measured, but Scherer and Snyder ( 1977 ) have carefully measured the relative intensities of the isotropic and anisotropic scattering in the $\mathrm{O}-\mathrm{H}$ stretching region. They analyzed the data by assuming that the polarizability of the water molecule is the sum of the polarizabilities of the two $\mathrm{O}-\mathrm{H}$ bonds, which were taken as cylindrically symmetrical with longitudinal and perpendicular polarizabilities $\alpha_{\|}$and $\alpha_{\perp}$ respectively. They found

$$
\alpha_{\sharp}{ }^{\prime} / \alpha_{\perp}{ }^{\prime}=5.5^{8} \pm 0.05,
$$

where the prime indicates the derivative with respect to the $\mathrm{O}-\mathrm{H}$ distance. From this value it is straightforward to calculate that the isotropic $\alpha^{\prime}\left(\nu_{I}\right)$ and anisotropic $\gamma^{\prime}\left(\nu_{I}\right)$ derivatives of the polarizability of a water molecule with respect to the $\nu_{1}$ motion are

$$
\left.\begin{array}{l}
\alpha^{\prime}\left(\nu_{1}\right)=0.906 \alpha_{\|}{ }^{\prime}, \\
\gamma^{\prime}\left(\nu_{1}\right)=0.895 \alpha_{\|}{ }^{\prime} .
\end{array}\right\}
$$

\section{Correlation of the properties of ice}

While it is important to establish how the properties of a water molecule change when it condenses to form ice, it is even more important to establish relations between these properties, and to understand how the changes from the vapor are caused. In this section, relations between the properties will be explored.

Some of the properties that have been described are for the nuclei at their equilibrium positions while some are the effects of changing the nuclear positions. The fundamental assumption of this section is that the properties of ice can be expanded in Taylor or Fourier series as a function of the ratio $r / R$ of the $\mathrm{O}-\mathrm{H}$ distance $r$, to the $\mathrm{O}-\mathrm{O}$ distance $R$. All $\mathrm{O}-\mathrm{H}$ distances $r$ are taken to be the same, so that only the effects of the symmetric stretching vibration $\nu_{1}$ are taken into account. Constraints on the expansion coefficients are imposed by the requirements that at $r / R=0$ and $\mathrm{I}$ the crystal is composed of neon atoms, and that at 
$r / R=\frac{1}{2}$ the crystal is centrosymmetric. It will be shown that, at least for the dipole moment, relations between properties can be obtained within the experimental uncertainty by using fewer parameters than properties, and that properties that have not yet been measured can be predicted.

\section{I. Potential energy}

At $r / R=0$ and $\mathrm{I}$ the oxygen and hydrogen nuclei coincide and the potential energy is infinite. Symmetry requires that the potential energy is even in $\frac{1}{2}-r / R$, and stability requires that at the equilibrium $\mathrm{O}-\mathrm{H}$ distance $r_{0}$ the potential energy is a minimum. There is no evidence for a minimum in the potential energy at $r / R=\frac{1}{2}$, so the simplest potential function that has the required properties is

$$
V=V_{0}\left(\frac{z^{2}-z_{0}^{2}}{z^{2}-\mathrm{I}}\right)^{2},
$$

where

$$
z=\mathrm{I} /(\mathrm{I}-2 r / R) \text {. }
$$

This function is rather complicated and the simpler function

$$
V=V_{0}\left[\mathrm{I}-\left(\frac{R-2 r}{R-2 r_{0}}\right)^{2}\right]^{2},
$$

has the correct properties except that it becomes $V_{0}\left[\mathrm{I}-\left(\mathrm{I}-2 r_{0} / R\right)^{-2}\right]^{2}$ instead of infinity at $r=\mathrm{o}$, or about $\mathrm{I}_{3} \mathrm{o} V_{0}$ for the case of ice. This is high enough, and so Equation ( $\mathrm{I}_{5}$ ) has been used. The second, third, and fourth derivatives of the potential with respect to the O-H distance are, at $r=r_{0}$

$$
\left.\begin{array}{l}
\partial^{2} V / \partial r^{2}=k_{2}=3^{2} V_{0} /\left[R-2 r_{0}\right]^{2}, \\
\partial^{3} V / \partial r^{3}=k_{3}=-\frac{6 k_{2}}{R-2 r_{0}}, \\
\partial^{4} V / \partial r^{4}=k_{4}=\frac{\mathrm{I} 2 k_{2}}{\left[R-2 r_{0}\right]^{2}} .
\end{array}\right\}
$$

The anharmonic term $v_{\mathrm{e}} x_{\mathrm{e}}$, which is defined by the relation

$$
\nu=\nu_{\mathrm{e}}+2 \nu_{\mathrm{e}} x_{\mathrm{e}},
$$

between the frequency $\nu$ of the transition between the ground and first excited states and the frequency $\nu_{\mathrm{e}}$ it would have if the anharmonicity were zero is, in units of wave numbers (see, for example, King, ig64, p. I62)

$$
\nu_{\mathrm{e}} x_{\mathrm{e}}=\frac{\mathrm{I}}{24} \frac{h}{8 \pi^{2} c \mu}\left\{\frac{3 k_{4}}{k_{2}}-5\left(\frac{k_{3}}{k_{2}}\right)^{2}\right\},
$$

where $h$ is Planck's constant, $c$ the speed of light, and $\mu$ the reduced mass of the oscillation.

The reduced mass of an isolated water molecule for the $\nu_{\mathrm{I}}$ vibration is

$$
\mu=2 m_{1}\left(m_{2}+2 m_{1} \sin ^{2} \beta\right) /\left(2 m_{1}+m_{2}\right),
$$

where $\beta$ is half the $\mathrm{H}-\mathrm{O}-\mathrm{H}$ angle and $m_{\mathrm{I}}$ and $m_{2}$ the masses of the hydrogen and oxygen atoms. This will not be accurately valid for the $\nu_{\mathrm{I}}$ vibration in disordered ice, partly because the disorder allows coupling between external and internal motions and partly because the $\mathrm{H}-\mathrm{O}-\mathrm{H}$ angle must open from $c$. $105^{\circ}$ at the equilibrium configuration to $c$. $109 \cdot 5^{\circ}$ at the centrosymmetric configuration. It should suffice, however, for a first-order theory. 
The frequency of the $\nu_{\mathrm{I}}$ stretching vibration in ice I is $3083 \mathrm{~cm}^{-1}$ (Wong and Whalley, 1975). In this motion many molecules must be coupled in phase (Wong and Whalley, r975; paper in preparation*) in order to give the sharp line that is observed, and this is confirmed by a calculation of the lattice dynamics (McGraw and others, 1977).

The value of $\nu_{\mathrm{e}} x_{\mathrm{e}}$ from Equations ( 15 ) to (19) is $-85.6 \mathrm{~cm}^{-1}$, so from this value and the experimental frequency, the harmonic frequency $\nu_{\mathrm{e}}$ is $3254 \mathrm{~cm}^{-1}$ and the harmonic force constant is $12.02 \mathrm{mdyn}^{-1}\left(0.1202 \mathrm{~N} \mathrm{~m}^{-1}\right)$. The equilibrium O-H distance in ice was calculated as $0.972 \AA$ by assuming approximately that the mean length in the first vibrational level, $0.986 \AA$ (see Section 2.I), is greater than the equilibrium length by the same amount, o.o $4 \AA$ (Kern and Karplus, I972), as in the vapor. Then $V_{0}$ as calculated from Equation (I6) is $2.4^{2}$ perg molecule ${ }^{-1},{ }_{1} 6 \mathrm{~kJ} \mathrm{~mol}^{-1}$, or $12200 \mathrm{~cm}^{-1}$. The potential function thus obtained is drawn in Figure $\mathbf{I}$. It is compared with an approximate potential function for an isolated water molecule represented as a Morse oscillator with the harmonic frequency $3832.2 \mathrm{~cm}^{-1}$ for the $\nu_{1}$ vibration and the anharmonicity constant $-87.8 \mathrm{~cm}^{-1}$ (Benedict and others, 1956$)$. The perturbation of the water molecule is very striking.

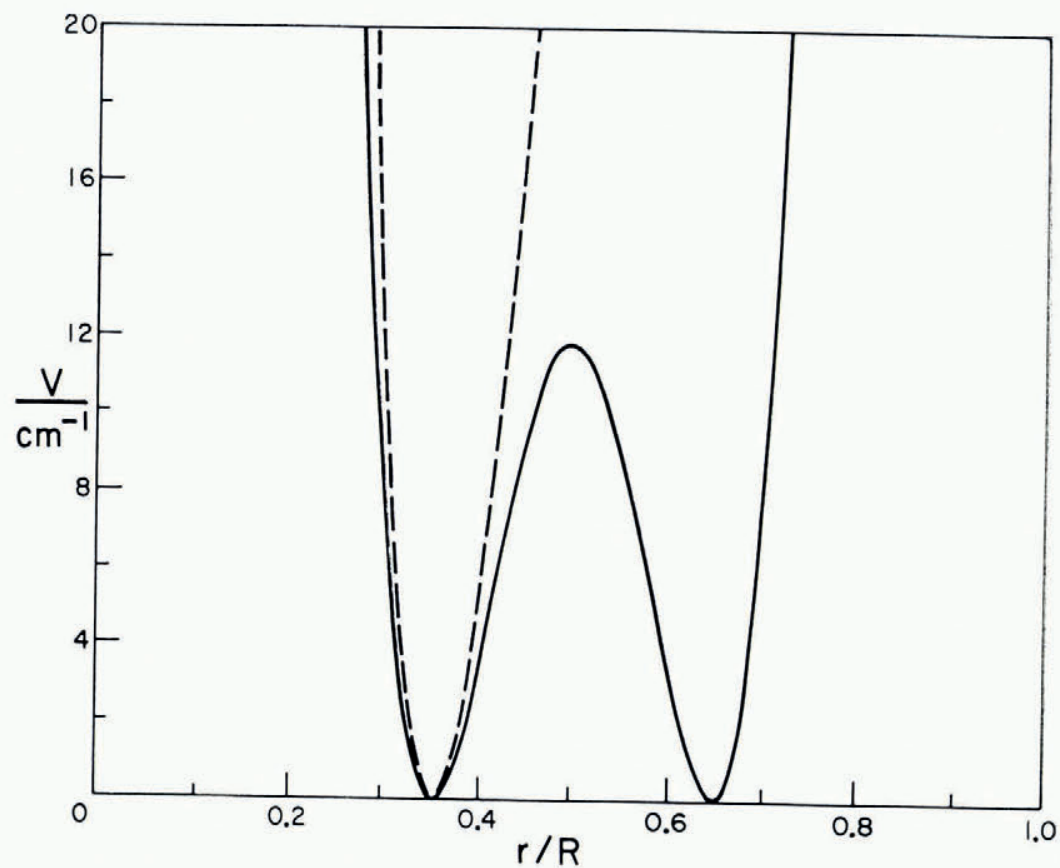

Fig. 1 . Potential function for the $\nu_{1}$ vibration of water molecules in the vapor. - - - according to the Morse potential described in Section 3.1 ; in the in-phase vibration of ice I according to the potential of Equation (15).

\subsection{Dipole moment}

The dipole moment of a water molecule is zero at $r / R=0$ and $\pm \mathrm{I}$ because the water molecules would have become neon atoms. At $r / R=\frac{1}{2}$ the hydrogen atoms are midway between the oxygen atoms and the dipole moment is also zero, and it changes sign as $r / R$ passes through $\mathrm{o}, \frac{1}{2}$, and $\mathrm{I}$. Consequently, the Fourier expansion of the dipole moment of a molecule is

$$
\mu=\sum_{n=1}^{\infty} \mu^{(n)} \sin (2 n \pi r / R) .
$$

\footnotetext{
* Paper described in the first footnote on p. 16.
} 
The orientational dielectric strength tells us that $\mu=2.45 \mathrm{D}$ at $r / R=0.359$. Consequently, if only the first term is taken, $\mu^{(\mathrm{I})}=3.16 \mathrm{D}$.

The intensity of the symmetric stretching vibration is determined by

$$
\frac{\partial \mu}{\partial r}=\mu^{(1)}(2 \pi / R) \cos (2 \pi r / R),
$$

which is $-4 \cdot 5 \mathrm{D} \AA^{-1}$. According to Section 2.3.2.3, the change of dipole moment on stretching all the $\mathrm{O}-\mathrm{H}$ bonds in ice is $\pm 4.4 \mathrm{D} \AA^{-1}$. The agreement with the calculated value is well within the uncertainty, and strongly suggests that $\partial \mu / \partial r$ is negative.

The intensity of the overtone infrared spectrum is determined by the second derivative of the dipole moment. From Equation (20) its value is

$$
\partial^{2} \mu / \partial r^{2}=-\mu^{(1)}(2 \pi / R)^{2} \sin 2 \pi r / R,
$$

which is $-13 \mathrm{D}^{-2}$. This is within $10 \%$ of the value $\pm 12 \mathrm{D}^{-2}$ obtained in Section 2.3.2.3. The agreement is reasonable good and suggests that $\partial^{2} \mu / \partial r^{2}$ is negative. The experimental evidence is consistent with only the first term in the series in Equation (20) being significant. The dipole moment is plotted against $r / R$ in Figure 2.

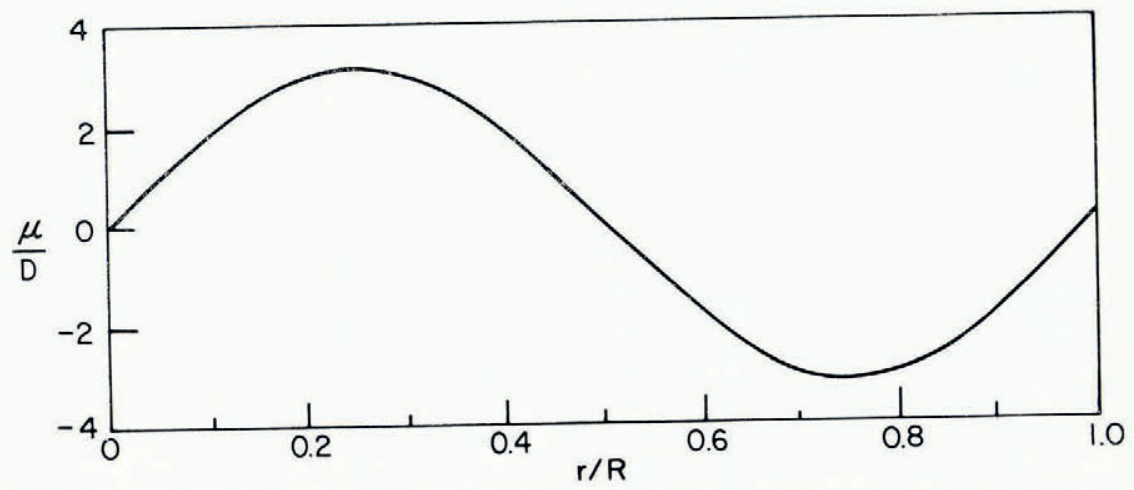

Fig. 2. Dipole moment of a water molecule in ice as a function of the ratio $r / R$ of the $O-H$ to the $O-O$ distance according to Equation (20) taking only the first term with $\mu^{(\mathrm{I})}=3.16 \mathrm{D}$.

If the dipole moment had been calculated from Equation (4) instead of from Equation (2) the predicted values of $\mathrm{d} \mu / \mathrm{d} r$ and $\partial^{2} \mu / \mathrm{d} r^{2}$ would have been higher by $23 \%$. The experimental value of $\partial^{2} \mu / \partial r^{2}$ is uncertain by at least this amount, but the value of $\partial \mu / \partial r$ is probably not. This suggests that a dipole moment of $c \cdot 2.5 \mathrm{D}$ is slightly preferable to one of $c .3 .0 \mathrm{D}$.

The third-order dipole-moment derivative is predicted to be

$$
\partial^{3} \mu / \partial r^{3}=-\mu^{(\mathrm{I})}(2 \pi / R)^{3} \cos (2 \pi r / R),
$$

which is $24 \mathrm{D}^{-3}$. This is the best estimate at present, and is, at least, better than no estimate.

In order to relate the dipole moment that oscillates with the molecule to the moment that reorients, a more specific model must be adopted. The simplest is to divide the total moment into an intrinsic moment plus a moment induced by the fields of neighboring molecules. As the local symmetry of a water molecule is $C_{2 \mathrm{v}}$, the moment induced by the neighbors must be even in the rotations about the axes perpendicular to the dipole moment, and so is independent of angle for small displacements. Consequently, only the "intrinsic" moment oscillates when the molecule oscillates about its axes. Its value from Section 2.3.2.2, is I.27(7) D. This value includes an enhancement of about $6 \%$ by the reaction field due to the electronic 
polarization of ice, but not to the far infrared and orientation polarizations as these respond too slowly to follow the rotational vibrations. Then I.I8(7) D must be induced by molecular interaction.

If this moment were induced by the electric field of the neighboring molecules, the field at the site of a molecule would be $0.79 \mathrm{M}$ e.s.u. $\mathrm{cm}^{-2}$ if the polarizability is taken as $\mathrm{I}^{-50} \AA^{3}$. There are two principal causes of this field, the field of the neighboring molecules before they are polarized by the molecule being considered, and the reaction field of its own dipole moment. If the two fields caused by molecules with unit dipole moment are $E_{\mathrm{I}}$ and $E_{2}$, then the moment of the molecule is

$$
\mu=\mu_{0} /\left[\mathrm{I}-\alpha\left(E_{\mathrm{I}}+E_{2}\right)\right],
$$

where $\mu_{0}$ is the intrinsic moment. Coulson and Eisenberg (1966) calculated the field at the site of a molecule due to the dipole moments of the neighboring molecules and averaged it over all the configurations allowed by the ice rules, each configuration being given equal weight. They obtained $0.297 \mathrm{M}$ e.s.u. $\mathrm{cm}^{-2}$ for a dipole moment of $\mathrm{I} .78 \mathrm{D}$, so that $E_{\mathrm{I}}$ was o. $6_{4} \AA^{-3}$. If $\epsilon \gg \mathrm{I}$, the reaction field per unit dipole moment is $a^{-3}$, where $a$ is the radius of a molecule. If, as usual, $4 \pi \mathrm{Na}^{3} / 3=\mathrm{I}, E_{2}$ is $0 . \mathrm{I} 3^{\mathrm{I}} \AA^{-3}$. If $\mu_{0}$ is I.I $8 \mathrm{D}$, these values yield $\mu=2.12 \mathrm{D}$. This agrees reasonably well with the dielectric constant if Equation (2) is correct, but not so well if Equation (4) is correct. The calculated moment would be increased to $2.4 \mathrm{D}$ if Coulson and Eisenberg's values for the field due to the quadrupole moment were included.

Isotopic substitution also changes the dipole moment, and according to Johari and Jones (1976) the orientation polarization is about $8 \%$ higher for $\mathrm{D}_{2} \mathrm{O}$ than for $\mathrm{H}_{2} \mathrm{O}$. As the molar volumes of $\mathrm{H}_{2} \mathrm{O}$ and $\mathrm{D}_{2} \mathrm{O}$ ice are almost identical (Blackman and Lisgarten, I957; Arnold and others, I 968), it follows from either Equation (2) or (4) that $g \mu^{2}$ must be about $8 \%$ higher for $\mathrm{D}_{2} \mathrm{O}$. According to either Equation (2) or (4), for small differences,

$$
\frac{\Delta \epsilon}{\epsilon}=2 \frac{\Delta \mu}{\mu}+\frac{\Delta g}{g} \text {. }
$$

The difference between the dipole moments of $\mathrm{H}_{2} \mathrm{O}$ and $\mathrm{D}_{2} \mathrm{O}$ is due to the different amplitudes of the nuclear motion in the $\nu_{1}$ and $\nu_{2}$ vibrations. The $v_{2}$ vibration is much weaker in the infrared than the $\nu_{I}$ and so its dipole-moment derivative is much smaller. It has therefore been neglected, as it must be because it has not been measured. The difference of the mean dipole moments in the first vibrational level, to terms in the cubic anharmonic constant and quadratic dipole-moment constant, is (Buckingham, I96o)

$$
\Delta \mu=-\frac{h c}{2 k_{2}}\left(\frac{k_{3}}{k_{2}} \frac{\partial \mu}{\partial r}-\frac{\partial^{2} \mu}{\partial r^{2}}\right) \Delta \nu_{\mathrm{e}}
$$

where $h$ is Planck's constant, $c$ the speed of light, $\nu_{\mathrm{e}}$ the harmonic frequency, and $\Delta$ the difference operator for isotopic substitution. For the potential function Equation ( 15 ), from Equations (18), (19), and (20):

$$
\begin{gathered}
k_{2}=\mathrm{I} 2 . \mathrm{I} \operatorname{mdyn} \AA^{-1}\left(=0.12 \mathrm{I} \mathrm{N} \mathrm{m}^{-1}\right), \\
k_{3} / k_{2}=-7.70 \AA^{-1}, \\
\nu_{\mathrm{e}}\left(\mathrm{H}_{2} \mathrm{O}\right)-\nu_{\mathrm{e}}\left(\mathrm{D}_{2} \mathrm{O}\right)=87 \mathrm{~cm}^{-1} .
\end{gathered}
$$

Hence

$$
\mu\left(\mathrm{H}_{2} \mathrm{O}\right)-\mu\left(\mathrm{D}_{2} \mathrm{O}\right)=\Delta \mu=-0.018 \mathrm{D}
$$

and

$$
\frac{\Delta \mu}{\mu}=0.007 \text { or }-0.006
$$


depending on whether Equation (2) or (4) is used. It follows from these values and Equation (23) that

$$
\frac{\Delta g}{g}=-0.066 \text { or }-0.068 \text {. }
$$

This implies that $\mathrm{D}_{2} \mathrm{O}$ has less orientational disorder than $\mathrm{H}_{2} \mathrm{O}$, and so that at least $\mathrm{D}_{2} \mathrm{O}$ does not have full orientational disorder.

If the permittivity can be represented by the Curie-Weiss Equation (6), then

$$
\frac{\Delta \epsilon}{\epsilon}=\frac{\Delta A}{A}+\frac{\Delta T_{0}}{T-T_{0}} .
$$

According to the foregoing discussion, the difference in the values of $A$ is due to the difference of dipole moments and the difference of the values of $T_{0}$ to the difference in the value of $g$. The differences are

$$
\begin{aligned}
\frac{\Delta A}{A} & =-0.0 \mathrm{I} 4, \\
\Delta T_{0} & =-\mathrm{I} 4 \mathrm{~K} .
\end{aligned}
$$

\subsection{Polarizability}

The components of the polarizability tensor can be expanded in a Fourier cosine series in $r / R$

$$
\alpha_{x y}=\alpha_{x y}{ }^{(0)}+\alpha_{x y}{ }^{(\mathrm{I})}[\mathrm{I}-\cos (2 \pi r / R)]+\alpha_{x y}{ }^{(2)}[\mathrm{I}-\cos (4 \pi r / R)]+\ldots .
$$

At $r / R=0$ and $\mathrm{I}$, the system is made of spherically polarizable neon atoms, and

$$
\left.\begin{array}{l}
\alpha_{x x}=\alpha_{y y}=\alpha_{z z}=\alpha^{(0)}, \\
\alpha_{x y}=\alpha_{y z}=\alpha_{z x}=0,
\end{array}\right\}
$$

where $\alpha^{(0)}$ is the polarizability of neon. At $r / R=\frac{1}{2}$, the hydrogen bonds are centrosymmetric, and

$$
\left.\begin{array}{l}
\alpha_{x x}=\alpha_{y y}=\alpha_{z z}=\alpha^{(0)}+\alpha^{(\mathrm{r})}, \\
\alpha_{x y}=\alpha_{y z}=\alpha_{z x}=0 .
\end{array}\right\}
$$

Consequently the first-order expansion for the diagonal components is

$$
\alpha_{x x}=\alpha_{y y}=\alpha_{z z}=\alpha^{(0)}+\alpha^{(\mathrm{I})}[\mathrm{I}-\cos (2 \pi r / R)],
$$

and the first-order expansion for the off-diagonal components is

$$
\alpha_{x y}=\alpha_{x y}{ }^{(2)}[\mathrm{I}-\cos (4 \pi r / R)] .
$$

At present, only the isotropic and the anisotropic invariants are observable, and for them the first-order expansion is

$$
\begin{aligned}
& \alpha=\alpha^{(0)}+\alpha^{(\mathrm{I})}[\mathrm{I}-\cos (2 \pi r / R)], \\
& \gamma=\gamma^{(2)}[\mathrm{I}-\cos (4 \pi r / R)] .
\end{aligned}
$$

The polarizability of neon at the sodium D line is (Moelwyn-Hughes, I96r, p. $3^{8} 3$ )

$$
\alpha^{(0)}=0.395 \AA^{3} \text {, }
$$

and from this and the isotropic part of the polarizability of water, which is $1.500 \AA^{3}$ according to the discussion in Section 2.4.I,

$$
\alpha^{(\mathrm{I})}=0.679 \AA^{3} \text {. }
$$

From Equation (29),

$$
\partial \alpha / \partial r=\alpha^{(\mathrm{I})}(2 \pi / R) \sin (2 \pi r / R),
$$


and so the theory predicts that

$$
\partial \alpha / \partial r \equiv \alpha^{\prime}\left(\nu_{1}\right)=\mathrm{I} .2 \mathrm{I} \AA^{2} .
$$

This quantity should determine the isotropic intensity of the $3083 \mathrm{~cm}^{-\mathrm{I}}$ Raman band in ice I, but it has not yet been measured. From Equations (32) and (14)

$$
\begin{gathered}
\alpha_{\|}{ }^{\prime}=\mathrm{I} .34 \AA^{2}, \quad \alpha_{\perp}{ }^{\prime}=0.239 \AA^{2}, \\
\partial \gamma / \partial r \equiv \gamma^{\prime}\left(\nu_{1}\right)=\mathrm{I} .08 \AA^{2} .
\end{gathered}
$$

The quantity $\gamma^{\prime}\left(\nu_{\mathrm{I}}\right)$ determines the anisotropic Raman intensity of the $\nu_{\mathrm{I}}$ vibrations, but it has not yet been measured. From Equations (30) and (34)

$$
\gamma^{(2)}=\mp 0.27 \AA^{3} \text {, }
$$

and so at the equilibrium configuration in ice

$$
\gamma=\mp 0.3^{2} \AA^{3} \text {. }
$$

This value is over three times the vapor value of $0.098 \AA^{3}$ (Murphy, 1977), and much greater than Cummins and Dunmur's estimate of o.o I $\AA^{3}$. It appears that present experimental measurements and Equation (30) are not consistent. The cause can only be determined by more experiments.

\section{Conclusion}

The principal conclusion from this paper is that many of the molecular properties of ice can be correlated by expanding them in the displacement of the in-phase $\nu_{\mathrm{I}}$ vibration. The most striking example is that the amplitude of the orientation polarization, which is proportional to $\mu^{2}$, and the integrated absorption intensity of the $\nu_{1}$ vibrations, which is proportional to $(\partial \mu / \partial r)^{2}$, are related by the equation

$$
\mu^{2}=\left(\frac{\partial \mu}{\partial r}\right)^{2} \frac{R}{2 \pi} \tan ^{2} \frac{2 \pi r}{R} .
$$

Similar treatments can be applied to other properties when they are measured, and may be applicable to other solids.

\section{REFERENGES}

Arnold, G. P., and others. 1968. Neutron diffraction study of ice polymorphs. III. Ice Ic, [by] G. P. Arnold, E. D. Finch, S. W. Rabideau and R. G. Wenzel. Journal of Chemical Physics, Vol. 49, No. 10, p. $4365-69$.

Benedict, W. S., and others. 1956. Spectra of deuterated water, [by] W. S. Benedict, N. Gailar and E. K. Plyler. Zournal of Chemical Physics, Vol. 24, No. 6, p. i1 $39-65$.

Bertie, J. E., and Whalley, E. I964. Infrared spectra of ices Ih and Ic in the range 4 ooo to $35^{\circ} \mathrm{cm}^{-1}$. Fournal of Chemical Physics, Vol. 40, No. 6, p. I637-45.

Bertie, J. E., and others. 1969 . Absorptivity of ice I in the range $4000-30 \mathrm{~cm}^{-1}$, [by] J. E. Bertie and H. J. Labbé and E. Whalley. Journal of Chemical Physics, Vol. 50, No. ro, p. 4501-20.

Blackman, M., and Lisgarten, N. D. 1957. The cubic and other structural forms of ice at low temperature and pressure. Proceedings of the Royal Society of London, Ser. A, Vol. 239, No. 1216, p. 93-107.

Brill, R., and Tippe, A. 1967. Gitterparameter von Eis I bei tiefen Temperaturen. Acta Crystallographica, Vol. 23, Pt. 3, p. 343-45.

Buckingham, A. D. I960. Optical, electrical, and magnetic properties of molecules. Annual Reports on the Progress of Chemistry, Vol. 57, p. 53-68.

Chan, R. K., and others. 1965. Effect of pressure on the dielectric properties of ice I, [by] R. K. Chan, D. W. Davidson and E. Whalley. Journal of Chemical Physics, Vol. 43, No. 7, p. 2376-83.

Chidambaram, R. I96I. A bent hydrogen bond model for the structure of ice-I. Acta Crystallographica, Vol. I4, Pt. 5, p. 467-68.

Clough, S. A., and others. 1973. Dipole moment of water from Stark measurements of $\mathrm{H}_{2} \mathrm{O}, \mathrm{HDO}$, and $\mathrm{D}_{2} \mathrm{O}$, [by] S. A. Clough, Y. Beers, G. P. Klein and L. S. Rothman. Journal of Chemical Physics, Vol. 59, No. 5, p. $2254-59$.

Coulson, C. A., and Eisenberg, D. 1966. Interaction of $\mathrm{H}_{2} \mathrm{O}$ molecules in ice I. The dipole moment of an $\mathrm{H}_{2} \mathrm{O}$ molecule in ice. Proceedings of the Royal Society of London, Ser. A, Vol. 291, No. 1427, p. 445-53. 
Cross, P. C., and others. 1937. The Raman spectrum and the structure of water, by P. C. Cross, J. Burnham and P. A. Leighton. Fournal of the American Chemical Society, Vol. 59, No. 6, p. I $134-47$.

Cummins, P. G., and Dunmur, D. A. 1973. Local electric field in ice I. Journal of Physical Chemistry, Vol. 77, No. 3 , p. $423^{-24}$.

Davidson, D. W. I971. The motion of guest molecules in clathrate hydrates. Canadian Journal of Chemistry, Vol. 49 , No. 8, p. $1224-42$.

Davidson, D. W., and others. 1964. Dielectric absorption and molecular motion in gas hydrates, [by] D. W. Davidson, M. Davies and K. Williams. Journal of Chemical Physics, Vol. 40, No. I 1, p. 3449-50.

Davies, M., and Williams, K. 1968. Dielectric relaxation in clathrates. Transactions of the Faraday Society, Vol. 64, Pt. 2, p. $529-48$.

Dorsey, N. E. 1940. Properties of ordinary water-substance in all its phases: water-vapor, water and all the ices. New York, Reinhold Publishing Corporation. (American Chemical Society. Monograph Series, No. 81.)

Glaeser, R. M., and Coulson, C. A. 1965 . Multipole moments of the water molecule. Transactions of the Faraday Society, Vol. 61, Pt. 3, p. 389-91.

Gobush, W., and Hoeve, C. A. J. 1972. Calculation of the dielectric correlation factor of cubic ice. Fournal of Chemical Physics, Vol. 57, No. 8, p. 3416-21.

Haas, C., and Hornig, D. F. I960. Inter- and intramolecular potentials and the spectrum of ice. Fournal of Chemical Physics, Vol. 32 , No. 6, p. I 763-69.

Hobbs, P. V. 1974. Ice physics. Oxford, Clarendon Press.

Hollins, G. T. 1964 . Configurational statistics and the dielectric constant of ice. Proceedings of the Physical Society, Vol. 84, Pt. 6, p. гоo -16.

Ikawa, S.-1., and Maeda, S. I968. Infrared intensities of the stretching and librational bands of $\mathrm{H}_{2} \mathrm{O}, \mathrm{D}_{2} \mathrm{O}$, and HDO in solids. Spectrochimica Acta, Vol. 24A, p. 655-65.

Johari, G. P., and Jones, S. J. 1976. Dielectric properties of polycrystalline $\mathrm{D}_{2} \mathrm{O}$ ice Ih (hexagonal). Proceedings of the Royal Society of London, Ser. A, Vol. 349, No. 1659, p. 467-95.

Johari, G. P., and Whalley, E. 1973. Orientational order in ice I, V, VI, and VII. (In Whalley, E., and others, ed. Physics and chemistry of ice: papers presented at the Symposium on the Physics and Chemistry of Ice held in Ottawa, Canada, I7-18 August 1972. Edited by E. Whalley, S. 7. Fones, L. W. Gold. Ottawa, Royal Society of Canada, p. 278-82.)

Johari, G. P., and Whalley, E. 1976. Dielectric properties of ice VI at low temperatures. Fournal of Chemical Physics, Vol. 64, Nol i i, p. 4484-89.

Johari, G. P., and Whalley, E. I978. The dipolar correlation factor of ice VI. Fournal of Glaciology, Vol. 2I, No. 85 , p. $692-93$.

$\mathrm{Kamb}$, W. B., and others. 1971. Ordered proton configuration in ice II, from single-crystal neutron diffraction, [by] [W.] B. Kamb and W. C. Hamilton and S. J. LaPlaca and A. Prakash. Fournal of Chemical Physics, Vol. 55 , No. 4 , p. 1934-45.

Kern, C. W., and Karplus, M. 1972. The water molecule. (In Franks, F., ed. Water: a comprehensive treatise. New York, Plenum Press, Vol. 1, p. 21-91.)

King, G. W. 1964. Spectroscopy and molecular structure. New York, Holt, Rinehart and Winston, Inc.

Kirkwood, J. G. 1939. The dielectric polarization of polar liquids. Fournal of Chemical Physics, Vol. 7, No. io, p. $911-19$.

Klug, D. D., and Whalley, E. 1973. The effect of orientational correlation on the far-infrared spectrum of ice. (In Whalley, E., and others, ed. Physics and chemistry of ice: papers presented at the Symposium on the Physics and Chemistry of Ice, held in Ottawa, Canada, I4-18 August 1972. Edited by E. Whalley, S. F. Jones, L. W. Gold. Ottawa, Royal Society of Canada, p. 93-97.)

Kroh, D., and Ron, A. I975. The overtone spectra of $\mathrm{H}_{2} \mathrm{O}, \mathrm{D}_{2} \mathrm{O}$ and mixtures of $\mathrm{H}_{2} \mathrm{O}$ in $\mathrm{D}_{2} \mathrm{O}$ ice. Chemical Physics Letters, Vol. 36, No. 4, p. 527-30.

Kuchitsu, K., and Bartell, L. S. 1962. Effect of anharmonic vibrations of polyatomic molecules. I. Model of force field and application to water. Fournal of Chemical Physics, Vol. 36, No. 9, p. 2460-69.

LaPlaca, S. J., and Post, B. I960. Thermal expansion of ice. Acta Crystallographica, Vol. I3, Pt. 6, p. 503-05.

LaPlaca, S. J., and others. I973. On a nearly proton-ordered structure for ice IX, [by] S. J. LaPlaca and W. C. Hamilton and [W.] B. Kamb and A. Prakash. Fournal of Chemical Physics, Vol. 58, No. 2, p. 567-80.

Leadbetter, A. J. I 965 . The thermodynamic and vibrational properties of $\mathrm{H}_{2} \mathrm{O}$ ice and $\mathrm{D}_{2} \mathrm{O}$ ice. Proceedings of the Royal Society of London, Ser. A, Vol. 287 , No. I410, p. 403-25.

McGraw, R., and others. 1977. An interpretation of the $\mathrm{O}-\mathrm{H}$ stretching region of the vibrational spectrum of ice Ih, by R. McGraw, W. G. Madden, S. A. Rice and M. G. Sceats. Chemical Physics Letters, Vol. 48, No. 2, p. 2 I $9-26$.

Minton, A. P. 1972. Relations between crystal structure, molecular electronic polarizability, and refractive properties of ice I. Journal of Physical Chemistry, Vol. 76, No. 6, p. 886-89.

Moelwyn-Hughes, E. A. r96r. Physical chemistry. Second edition. Oxford, Pergamon Press.

Murphy, W. F. 1977. The Rayleigh depolarization ratio and rotational Raman spectrum of water vapor, and the polarizability components for the water molecule. Fournal of Chemical Physics, Vol. 67, No. 12, p. $5877-82$.

Nagle, J. F. 1974. Dielectric constant of ice. Journal of Chemical Physics, Vol. 6r, No. 3, p. 883-88.

Nagle, J. F. 1978. Configurational statistics. Journal of Glaciology, Vol. 21, No. 85, p. 73-83.

Ockman, N. 1958. The infrared and Raman spectra of ice. Advances in Physics, Vol. 7, No. 26, p. 199-220.

Onsager, L., and Dupuis, M. I96o. The electrical properties of ice. Rendiconti della Scuolo Internazionale de Fisica "Enrico Fermi", Corso X, Varenna, I 5-27 Giugno 1959, p. 294-3i 5.

Onsager, L., and Dupuis, M. I 962 . The electrical properties of ice. (In Pesce, B., ed. Electrolytes: proceedings of an international symposium on electrolytes, held in Trieste, fune 1959. Oxford, etc., Pergamon Press, p. 27-46.)

Orrtung, W. H., and Meyers, J. A. 1963. The Kerr constant of water. fournal of Physical Chemistry, Vol. 67, No. 9, p. 1905-10. 
Peterson, S. W., and Levy, A. L. 1957. A single-crystal neutron diffraction study of heavy ice. Acta Crystallographica, Vol. 10, Pt. I, p. 70-76; Pt. 4, p. 344.

Rahman, A., and Stillinger, F. H. 1972. Proton distribution in ice and the Kirkwood correlation factor. Journal of Chemical Physics, Vol. 57, No. 9, p. 4009-1 7 .

Ritzhaupt, G., and Devlin, J. P. 1977. Infrared spectrum of $\mathrm{D}_{2} \mathrm{O}$ vibrationally decoupled in glassy $\mathrm{H}_{2} \mathrm{O}$. Journal of Chemical Physics, Vol. 67, No. 10, p. $4779^{-80}$.

Schaaf, J. W., and Williams, D. 1973. Optical constants of ice in the infrared. Fournal of the Optical Society of America, Vol. 63 , No. 6, p. 726-32

Scherer, J. R., and Snyder, R. G. 1977. Raman intensities of single crystal ice Ih. Fournal of Chemical Physics, Vol. 67 , No. II, p. 4794-8I I.

Slater, J. C. I941. Theory of the transition in $\mathrm{KH}_{2} \mathrm{PO}_{4}$. Journal of Chemical Physics, Vol. 9, No. 1, p. $16-33$. Stillinger, F. H., and Cotter, M. A. 1973. Local orientational order in ice. Fournal of Chemical Physics, Vol. 58 ,
$\quad$ No. 6, p. $253^{2-41}$.

Taubenberger, R., and others. 1973. Effect of hydrostatic pressure on the dielectric properties of ice Ih single crystals, [by] R. Taubenberger, M. Hubmann and H. Gränicher. (In Whalley, E., and others, ed. Physics and chemistry of ice: papers presented at the Symposium on the Physics and Chemistry of Ice, held in Ottawa, Canada, I $4^{-18}$ August 1972. Edited by E. Whalley, S. J. Jones, L. W. Gold. Ottawa, Royal Society of Canada, p. 194-98.)

Whalley, E. 1957. The difference in the intermolecular forces of $\mathrm{H}_{2} \mathrm{O}$ and $\mathrm{D}_{2} \mathrm{O}$. Transactions of the Faraday Society, Vol. 53 , No. 12, p. 1578-85.

Whalley, E. 1958. Zero-point energy: a contribution to intermolecular forces. Transactions of the Faraday Society, Vol. 54, No. 11, p. 1613-21.

Whalley, E. 1973. Lattice dynamics of ice. (In Whalley, E., and others, ed. Physics and chemistry of ice: papers presented at the Symposium on the Physics and Chemistry of Ice, held in Ottawa, Canada, I4-18 August 1972. Edited by E. Whalley, S. F. Jones, L. W. Gold. Ottawa, Royal Society of Canada, p. 73-81.)

Whalley, E. 1974. The O-H distance in ice. Molecular Physics, Vol. 28, No. 4, p. 1 105-o8.

Whalley, E. 1976. The hydrogen bond in ice. (In Schuster, P., and others, ed. The hydrogen bond. III. Dynamics, thermodynamics and special systems. Edited by P. Schuster, G. Zundel and C. Sandorfy. Amsterdam, North-Holland
Publishing Co., p. 1427-70.) Whalley, E. 1977. A detailed assignment of the $\mathrm{O}-\mathrm{H}$ stretching bands of ice I. Canadian Journal of Chemistry,
Vol. 55, No. 19, p. 3429-41.

Wong, P. T. T., and Whalley, E. 1972. The intensities of the infrared-active intermolecular translational bands in solid chlorine. Evidence for intermolecular bonding. Canadian Fournal of Physics, Vol. 50, No. I6, p. 1856-6 I

Wong, P. T. T., and Whalley, E. 1975. Optical spectra of orientationally disordered crystals. V. Raman spectrum of ice Ih in the range $4000-350 \mathrm{~cm}^{-1}$. Journal of Chemical Physics, Vol. 62, No. 6, p. 2418-25. Wong, P. T. T., and Whalley, E. 1976. Raman spectra of ice VIII. Journal of Chemical Physics, Vol. 64, No. 6,
p. $2359-66$.

Zeiss, G. D., and Meath, W.J. 1975. The $\mathrm{H}_{2} \mathrm{O}-\mathrm{H}_{2} \mathrm{O}$ dispersion energy constant and the dispersion of the refractive index of dilute water vapor. Molecular Physics, Vol. 30, No. I, p. 16 I-69.

\section{DISCUSSION}

J. NAGLE: If you use the Onsager formula for the dielectric constant instead of the Kirkwood formula, i.e. using $2 \mathrm{~g} / 3$ instead of $g$, are there any irreconcilable problems in your subsequent analysis of your experiments?

E. Whalley: As is stated in the written, but was not in the spoken, version, if $\Delta \epsilon=$ $4 \pi N g \mu^{2} / 3 k T$ is used, $g$ is $3.00 \mathrm{D}$ and $\mathrm{d} \mu / \mathrm{d} r$ is predicted to be $-0.56 \mathrm{D} \AA^{-1}$ compared with the experimental $\pm 4.6 \mathrm{D} \AA^{-1}$. The value $-0.56 \mathrm{D} \AA^{-1}$ corresponds to an integrated absorptivity about 1.5 times the observed, which is certainly well outside the difference between the experimental measurements and is probably well outside the experimental error. It seems likely then that either more than one term must be used in the Fourier expansion of the dipole moment or $2 \pi$ must be preferred to $4 \pi / 3$ as the factor in the equation for the permittivity. 